\title{
CURRENT UNDERSTANDING OF THE PEDIATRIC METABOLIC SYNDROME (REVIEW)
}

\author{
Chaychenko T., Kharkova M. \\ Kharkiv National Medical University, Ukraine \\ https://doi.org/10.35339/ic.8.1.18-21
}

\begin{abstract}
According to the World Health Organization, $68 \%$ of the causes of global mortality are due to noncommunicable diseases that include cardiovascular pathology, obesity, atherosclerosis and diabetes mellitus. The combination of abdominal obesity, hypertension, hyperglycemia and hyperlipidemia against a background of insulin resistance and chronic subclinical inflammation are components of metabolic syndrome (MetS). MetS in pediatric population is also a complex problem associated with the potential cardiovascular risk in young adults. There are lots of debates around definitions and diagnostic cut-offs for the MetS components due to age dependent fluctuations of the metabolic and cardiovascular parameters. This leads to the unclear incidence of the syndrome in children. Meantime, healthy lifestyle, nutrition and sleep are best strategies for both preventing and treating MetS in children and adolescents. Despite the large number of studies in this area, pediatric metabolic syndrome remains the subject of controversy.
\end{abstract}

Keywords: Metabolic syndrome, diagnosis, children.

According to the World Health Organization, the prevalence of overweight and obesity among children and adolescents aged 5 to 19 years increased dramatically from $4 \%$ in 1975 to more than $18 \%$ in 2016 , when the number of children with obesity and overweight reached 340 million [1]. $17.77 \%$ children in Ukraine were obese in 2014 [2] with an annual upward trend in the incidence of new cases [3].

Overweight and obese children have a high probability to become obese adults and develop cardiovascular problems [4] and diabetes in the early adulthood [5]. The combination of abdominal obesity, insulin resistance, hyperglycemia, hypertension, violation of hemostasis was combined into the concept of "metabolic syndrome" (MetS). The main concept of the MetS theory is in the timely patient stratification into a group of high cardiovascular risk [6].

Despite numerous studies, common criteria for diagnosing MetS in childhood are still under

Corresponding Author:

Mariya Kharkova MD, PhD student,

Department of Pediatrics № 1 and Neonatology,

Kharkiv National Medical University, Ukraine.

E-mail: M.kharkova19@gmail.com debates. Current diagnostic criteria for the pediatric practice were published in the IDF report in 2007 and were based on similar MetS criteria for adults. These criteria include: waist circumference $>90$ percentile, triglycerides level $>1.7 \mathrm{mmol} / \mathrm{l}$, high-density lipoproteins (HDL) level $<1.03 \mathrm{mmol} / \mathrm{l}$, fasting glucose level $>5.6 \mathrm{mmol} / \mathrm{l}$ or diagnosed diabetes mellitus, systolic blood pressure $>130 \mathrm{~mm} \mathrm{Hg}$ and diastolic blood pressure $>85 \mathrm{~mm} \mathrm{Hg}$ [7].

Unfortunately, these cut-offs do not meet modern requirements for the parameters included and it has been shown in the results of the investigation in the IDEFICS study [8]. That is why the prevalence of MetS differs in dependently on the definition (ranged from 6 to 39\%) [9]. Furthermore, there are lot of controversies around the pediatric MetS diagnosis [10, 11]. Despite confirmed association between childhood and adolescent MetS with long-term outcomes, further prospective studies are needed to clarify the true value of diagnosing MetS in youth [12].

Insulin Resistance was mentioned as a main background for all MetS components development [13]. Homeostasis model assessment-insulin resistance (HOMA-IR) was proposed to evaluate insulin resistance [14] and became the most 
popular for both adults and children despite the fact that many other surrogate indices were elaborated [15-18].

Meanwhile, there is still unknown how to properly measure Insulin Resistance in children, according to the conclusion of the Insulin Resistance in Children Consensus Conference Group (2010) [19].

The problems of determining the clinical criteria for MetS in children include physiological changes that occur throughout childhood and puberty. For example, insulin resistance increases in early puberty, but stabilizes in the middle of adolescence as well as lipids and can also vary depending on gender [20].

Insulin secretion is affected well before blood glucose concentrations are within the range of prediabetes and diabetes. It is well established that abnormal $\beta$-cell function and peripheral insulin resistance are associated with elevated 2-h glucose levels, even within the normal glucose tolerance range, without meeting the criteria for impaired glucose tolerance and impaired fasting glucose $[21,22]$. There is a linear dependence of fasting and average insulin concentration on BMI. Thus, there is a strongest insulin response at the standard glucose load at the second phase in overweight and obese subjects that differs from normal weight and skinny children [23].

It may well explain why the elevated blood glucose 2 hours after the standard load is a strong predictor for the development of T2DM in adults [22], but not in children [24].

According to the European Society of Cardiology elevated triglycerides and LDLs and decreased HDLs are direct cause of cardiovascular disease in adulthood [25]. Decreased HDL and elevated triglycerides are components of the metabolic syndrome in children according to the IDF Consensus [7]. It is estimated that about $42 \%$ of obese children have lipid abnormalities, particularly those with visceral obesity [26].

The leading document that allows assessment of the level of lipid metabolism, taking into account the age of the child are the recommendations of the National Cholesterol Education Program (NCEP) [27]. These recommendations effectively establish variants of hyperlipidemia in obese children [28].
Associations between MetS and non-alcoholic fatty liver disease, hyperuricemia, sleep apnea, and several other potential biomarkers, useful for early identification of patients with a higher cardiometabolic risk, have been described in obese children. But these are still not considered when MetS is defined [29].

A number of recent studies also indicate that epigenetic mechanisms may play an important role in MetS initiation [30] and its course in both adults [31,32] and children [33]. Meanwhile, excessive nutrition, low physical activity, social environment and stress have even stronger influence on the development of obesity and related metabolic disorders, that can be preventable [1].

Regardless of many different approaches to treating metabolic syndrome (MetS) in children and adolescents, early screening and treatment of the individual components that contribute to its development play a key role in reducing cardiometabolic risk. Therefore weight loss and lifestyle interventions can have a positive effect on the components of MetS [34].

Also, according to numerous studies, special attention should be paid to the sleep duration as poor or insufficient quality of sleep (less than 8 hours) in children and adolescents are associated with MetS elements such as hypertension with/ or non-dipping profiles of BP [29]. Furthermore, acute sleep restriction increases food intake associated with the deteriorated lipid content [35].

\section{Conclusions}

Metabolic syndrome in pediatric population is a complex of problems associated with the potential cardiovascular risk. There are lots of debates around definitions and diagnostic cut-offs for the MetS components due to age dependent fluctuations of the metabolic and cardiovascular parameters. This leads to the unclear incidence of the syndrome in children. Healthy lifestyle, nutrition and sleep are best strategies for preventing and treating MetS in children and adolescents.

Despite the large number of studies in this area, pediatric metabolic syndrome remains the subject of controversy.

\section{Conflict of interests}

The authors of the article declare no conflict of interests.

\section{References}

1. WHO. Facts and figures on childhood obesity. Comm End Child Obes. 2019.

2. Zelins 'ka N. B. (2015) Medical care for children with endocrine pathology in Ukraine in 2014. Ukr J Pediatr Endocrinol.;(2):5-13. 
3. Zelins 'ka N. B. (2016) Analysis of statistical indicators of pediatric endocrinology care in Ukraine in 2015 year. Ukr J Pediatr Endocrinol:;(2):7-17.

4. Lindberg L, Danielsson P, Persson M, Hagman E, Marcus C. (2017). Childhood obesity increases risk of premature death in young adulthood - A prospective cohort study. Eur J Public Health.; 27(3). doi:10.1093/eurpub/ckx189.254

5. Hagman E, Danielsson P, Brandt L, Ekbom A, Marcus C. (2016) Association between impaired fasting glycaemia in pediatric obesity and type 2 diabetes in young adulthood. Nutr Diabetes; 6(8):E227. doi:10.1038/nutd.2016.34

6. Alberti KG, Zimmet P, Shaw J. (2005). The metabolic syndrome - A new worldwide definition. Lancet; 366: 1059-1062. doi:10.1016/S0140-6736(05)67402-8

7. Alberti SG, Zimmet P. (2007) The IDF Consensus definition of the Metablic Syndrome in Children and Adolescents. Int Diabetes Fed; 10:324-335.

8. Ahrens W, Moreno L, M?rild S, et al. (2014) Metabolic syndrome in young children: Definitions and results of the IDEFICS study. Int J Obes; 38: S4-14. doi:10.1038/ijo.2014.130

9. Reinehr T, De Sousa G, Toschke AM, Andler W. (2007) Comparison of metabolic syndrome prevalence using eight different definitions: A critical approach. Arch Dis Child.; 92: 1067-1072. doi:10.1136/adc.2006.104588

10. Chaychenko T. Controversies in Pediatric Metabolic syndrome diagnosis. Tavricheskiy Med Vestn. 2013;16(3(1-63)):159-162. doi:http://dspace.nbuv.gov.ua/handle/123456789/74799

11. Chaychenko T. (2016) Cardiovascular risk diagnostic controversies in pediatric metabolic syndrome. J Metab Syndr.

12. Marcovecchio ML, Chiarelli F. (2013) Metabolic syndrome in youth: Chimera or useful concept? Curr Diab Rep.; 13, 56-62. doi:10.1007/s11892-012-0331-2

13. Reaven GM. (1995) Pathophysiology of insulin resistance in human disease. Physiol Rev.; 75(3):473-86. doi:10.1152/physrev.1995.75.3.473

14. Matthews DR, Hosker JP, Rudenski AS, Naylor BA, Treacher DF, Turner RC. (1985). Homeostasis model assessment: insulin resistance and ?-cell function from fasting plasma glucose and insulin concentrations in man. Diabetologia. 1985; 28(7):412-9. doi:10.1007/BF00280883

15. Matsuda M, DeFronzo RA. (1999) Insulin Sensitivity Indices Obtained From Oral Glucose Tolerance Testing. Diabetes Care.; 22(9):1462-70. doi:10.2337/diacare.22.9.1462

16. Katz A, Nambi SS, Mather K, et al. (2000) Quantitative insulin sensitivity check index: A simple, accurate method for assessing insulin sensitivity in humans. J Clin Endocrinol Metab.; 85(7):2402-10. doi:10.1210/jcem.85.7.6661

17. Rabasa-Lhoret R, Bastard JP, Jan V, et al. (2003). Modified Quantitative Insulin Sensitivity Check Index Is Better Correlated to Hyperinsulinemic Glucose Clamp than Other Fasting-Based Index of Insulin Sensitivity in Different Insulin-Resistant States. J Clin Endocrinol Metab. 88(10):4917-23. doi:10.1210/ jc.2002-03031618.

18. Mcauley KA, Williams SM, Mann JI, et al. (2001). Diagnosing insulin resistance in the general population. Diabetes Care. 24(3):460-4.. doi:10.2337/diacare.24.3.460

19. Levy-Marchal C, Arslanian S, Cutfield W, et al. (2010). Insulin resistance in children: Consensus, perspective, and future directions. J Clin Endocrinol Metab.; 95(12):5189-98. doi:10.1210/jc.2010-1047

20. Ata N, Maguire B, Hamilton DC, Kuhle S. (2018).Percentile curves for cardiometabolic disease markers in Canadian children and youth: a cross-sectional study. BMC Pediatr.; 18, 314 doi:10.1186/ s12887-018-1289-2

21. Giannini C, Weiss R, Cali A, et al. (2012) Evidence for early defects in insulin sensitivity and secretion before the onset of glucose dysregulation in obese youths: A longitudinal study. Diabetes.; 61(3):606-14 doi:10.2337/db11-1111

22. Weiss R, Taksali SE, Tamborlane W V., Burgert TS, Savoye M, Caprio S. (2005) Predictors of changes in glucose tolerance status in obese youth. Diabetes Care; 8(4):902-9. doi:10.2337/diacare.28.4.902

23. Chaychenko TV, Rybka OS. (2017) Insulin sensitivity in skinny, normal weight, overweight and obese children. New Armen Med J.;11(2): 40-45.

24. Galderisi A, Giannini C, Weiss R, et al. (2018) Trajectories of changes in glucose tolerance in a multiethnic cohort of obese youths: an observational prospective analysis. Lancet Child Adolesc Heal. 2(10): P726-735. doi:10.1016/S2352-4642(18)30235-9 
25. Catapano AL, Graham I, De Backer G, et al. (2016) 2016 ESC/EAS Guidelines for the Management of Dyslipidaemias. Eur Heart J.; 37, 2999-3058. doi:10.1093/eurheartj/ehw272

26. Pires A, Martins P, Pereira AM, et al. (2015). Insulin resistance, dyslipidemia and cardiovascular changes in a group of obese children. Arq Bras Cardiol. 104(4), 266-273. doi:10.5935/abc.20140206

27. Jolliffe, C. J., Janssen, I. (2006). Distribution of Lipoproteins by Age and Gender in Adolescents. Circulation, 114 (10), 1056-1062. doi:10.1161/CIRCULATIONAHA.106.620864

28. Chaychenko T, Kharkova M, Rybka O. (2020). Variants of hyperlipidemia in children with insulin resistance. Inter Collegas; 7(1):23-25. doi:10.35339/ic.7.1.23-25

29. Bussler, S., Penke, M., Flemming, G., Elhassan, Y.S., Kratzsch, J., Sergeyev, E., ... Kiess, W. (2017). Novel Insights in the Metabolic Syndrome in Childhood and Adolescence. Horm Res Paediatr, 88,181-193. https://doi.org/10.1159/000479510.

30. Kunes, J., Vaneckova, I., Mikulaskova, B., Behuliak, M., Maletinska, L., Zicha, J. (2005). Epigenetics and a new look on metabolic syndrome. Physiol Res, 64, 611-620. doi:10.33549/ physiolres.933174

31. Izquierdo AG, Crujeiras AB. Chapter 10 - Epigenetic biomarkers in metabolic syndrome and obesity. In: Sharma S, ed. Prognostic Epigenetics. Vol 15. Translational Epigenetics. Academic Press; 2019:269-287. doi:https://doi.org/10.1016/B978-0-12-814259-2.00011-X

32. Carson C, Lawson HA. Epigenetics of metabolic syndrome. Physiol Genomics. 2018 Nov 1;50(11):947-955. doi:10.1152/physiolgenomics.00072.2018

33. Puumala SE, Hoyme HE. (2015). Epigenetics in Pediatrics. Pediatrics in Review, 36 (1): 14-21. doi:10.1542/pir.36-1-14

34. Fornari, E., Maffeis, C. (2019). Treatment of Metabolic Syndrome in Children, Front. Endocrinol https://doi.org/10.3389/fendo.2019.00702.

35. Wang, F., Liu, H., Wan, Y., Li, J., Chen, Y., Zheng, J., ... Li, D. (2016) Sleep duration and overweight/obesity in preschool-aged children: a prospective study of up to 48,922 children of the Jiaxing birth cohort. Sleep, 1, 39(11), 2013-2019.

Received: 04-Jan-2021

Accepted: 04-Mar-2021 